\title{
Progress and Remaining Gaps in Estimating the Global Disease Burden of Influenza
}

\author{
Joseph Bresee, Julia Fitzner, Harry Campbell, Cheryl Cohen, Vanessa Cozza, Jorge Jara, \\ Anand Krishnan, Vernon Lee, for the WHO Working Group on the Burden of Influenza Disease
}

\begin{abstract}
Influenza has long been a global public health priority because of the threat of another global pandemic. Although data are available for the annual burden of seasonal influenza in many developed countries, fewer disease burden data are available for low-income and tropical countries. In recent years, however, the surveillance systems created as part of national pandemic preparedness efforts have produced substantial data on the epidemiology and impact of influenza in countries where data were sparse. These data are leading to greater interest in seasonal influenza, including implementation of vaccination programs. However, a lack of quality data on severe influenza, nonrespiratory outcomes, and high-risk groups, as well as a need for better mathematical models and economic evaluations, are some of the major gaps that remain. These gaps are the focus of multilateral research and surveillance efforts that will strengthen global efforts in influenza control in the future.
\end{abstract}

$\mathrm{I}$ nfluenza has long been a global public health priority because of the ever-present threat of another global pandemic. In addition, many countries (especially in more affluent, temperate areas) prioritize influenza prevention and control programs because of the annual effects of seasonal influenza. The 3 influenza pandemics that occurred during the 20th century clearly illustrated the major impact from the global spread of a new influenza A virus (1) and spurred early vaccine development $(2,3)$. The reemergence of avian influenza A(H5N1) in Asia in 2004 served as a reminder of this threat and brought about an acceleration of national and international efforts to prepare for the next pandemic (4). These efforts, including the expansion

Author affiliations: Centers for Disease Control and Prevention, Atlanta, Georgia, USA (J. Bresee); World Health Organization,

Geneva, Switzerland (J. Fitzner, V. Cozza); University of Edinburgh, Edinburgh, Scotland, UK (H. Campbell); National Institute for Communicable Diseases, Johannesburg, South Africa (C. Cohen); Universidad del Valle de Guatemala, Guatemala City, Guatemala (J. Jara); All Indian Institute of Medical Sciences, New Delhi, India (A. Krishnan); Ministry of Health, Singapore (V. Lee)

DOI: https://doi.org/10.3201/eid2407.171270 of influenza surveillance and laboratory capacity, contributed to a more effective response during the 2009 influenza $\mathrm{A}(\mathrm{H} 1 \mathrm{~N} 1)$ pandemic (5).

Although the threat of novel influenza A viruses and pandemics has mobilized national preparedness efforts, in many parts of the world the importance of seasonal epidemics of influenza has been relatively underappreciated. On the basis of findings from recent influenza respiratory mortality studies, including estimates from a study conducted by Iuliano et al ( 6 ), the World Health Organization (WHO) has indicated that 290,000-650,000 respiratory deaths from seasonal influenza epidemics occur annually (7). Most high-income countries, where substantial work to document the disease burden from annual influenza epidemics has been conducted, have longstanding and robust influenza vaccination programs (8); in these settings, the use of influenza antiviral drugs and antibiotics to treat influenza-associated lower respiratory tract infections is relatively routine. These strategies have likely resulted in a reduction in the burden of disease as well as improved clinical outcomes for patients with influenza. In tropical and low- and middle-income countries (LMICs), seasonal influenza has often been viewed as a disease of relevance primarily to industrialized countries. The historical paucity of data on influenza from these settings has likely contributed to this view. More data on influenza burden in these locations are needed to make compelling arguments to policy makers for investments in seasonal influenza control and prevention. These data are particularly important in the light of challenges related to the variable effectiveness of current vaccines (9) and the programmatic and economic difficulties in conducting annual influenza vaccination programs or in implementing appropriate use of antivirals for treatment in LMICs. The resulting relative underuse of vaccines in many LMICs represents important missed opportunities for disease prevention (10). Furthermore, the lack of antiviral drug treatment and influenza vaccination programs for reduction of seasonal influenza burden in these settings also jeopardizes the capacity for effective responses when the next pandemic emerges because national pandemic response plans rely, in part, on the timely and efficient use of 
medical countermeasures, such as antiviral drugs and vaccines for pandemic viruses $(11,12)$.

\section{Progress, but Gaps Remain}

The growth of influenza surveillance and research in the past 10 years has generated substantial new data on the epidemiology and risk from influenza around the world, notably in tropical countries and LMICs (13-16). These data have confirmed that influenza is a major cause of hospitalization and severe acute respiratory disease in all settings, whether rich or poor, tropical or temperate, urban or rural (17-19), and that the risk for severe influenza outcomes might be higher in LMICs than in high-income countries (20). In South Africa, for instance, rates of influenza-associated mortality among the elderly were 3-4 times higher than those among the elderly in the United States (21). One global estimate of childhood influenza deaths indicated that $99 \%$ of all influenza-associated deaths among children $<5$ years of age were in LMICs (18). That this finding is true for influenza, as it is for other infectious diseases, is not surprising, and similarly, is likely the result of differential access to medical care and preventive strategies, coupled with the prevalence of certain high-risk conditions and the underlying age structure of the populations. In some LMICs that have collected robust disease burden information in the past decade, vaccine programs have expanded (22-24). In addition, disease burden data from these settings were one driving factor for updating of the WHO influenza vaccine recommendations issued in 2012 by the WHO Strategic Advisory Group of Experts (25).

However, although data on influenza disease burden have expanded in recent years, considerable gaps persist. First, high-quality and up-to-date estimates of the extent of severe influenza at global and regional levels are needed to inform global policymakers and public health advocates as they set their priorities. Although new estimates of the global respiratory mortality rates attributable to influenza are available (6), additional models that take advantage of the expansion in influenza surveillance and laboratory confirmation, especially in tropical countries and LMICs, should yield more accurate country- and region-specific disease estimates. Second, at the country level, too many LMICs have yet to develop reliable national estimates of the full extent of influenza disease that would enable evidence-based decisions about local influenza prevention investments. Third, the ability to target vaccination campaigns to key populations within a country depends on having reliable data on the burden of disease and on the possible effect of vaccination among specific high-risk target groups. The value of risk group-specific estimates was evident during the 2009 pandemic, when data on the high risk for severe outcomes among pregnant women led to aggressive efforts to vaccinate and appropriately treat this group and convince obstetricians to recommend and offer vaccines $(26,27)$; this effort provided data for the WHO Strategic Advisory Group of Experts' 2012 recommendations (25). Conversely, the scarcity of adequate data on severe disease among pregnant women during seasonal epidemics was one reason cited by the Global Alliance for Vaccines and Immunizations for their decision against opening an investment window to fund lowincome countries to vaccinate pregnant women as part of their most recent vaccine investment strategy (28). Data have long indicated that persons with specific underlying diseases are at high risk for severe influenza, but without a better understanding of the burden of the disease in these groups in countries considering vaccination policies, expecting policymakers to invest in programs to target them is unrealistic. Few data have been collected outside of high-income countries on other components of the health burden, especially the contribution of influenza infections to illness and death from underlying diseases made worse by influenza, such as cardiac or chronic pulmonary diseases (29), and on non-health-related effects of influenza, such as the economic burden and effect on productivity (30). Data on each of these components will advance decisions on the rational use of resources to prevent influenza, and the need for these data was highlighted in the recent revision of the WHO Influenza Research Agenda (31).

\section{Ongoing Work to Address the Gaps and Future Needs}

Substantial work is under way to fill these gaps. WHO has created a robust program to collect data on global and national influenza burden and to better determine the burden among risk groups. Two manuals have been developed to guide member states' efforts to measure influenza disease (32) and economic burden (33) from data collected through ongoing influenza surveillance. Both manuals are being used by countries, in part, because of the Pandemic Influenza Preparedness Implementation Plan that has facilitated country-level disease burden estimation in many countries around the world (34). These efforts have led to recent publications from LMICs, supported by WHO, that provide important influenza disease burden data (34). WHO has also sponsored reviews of influenza-associated disease burden among pregnant women and their infants $(35,36)$. Additional multinational collaborations are under way that will continue to develop more credible global influenza mortality and hospitalization estimates based on recent work to develop national estimates, as well as information on influenza burden among key high-risk groups (Figure) (6). These efforts take advantage of the recent increase in local- or country-level studies that have extended data beyond temperate, high-income settings. WHO is also 


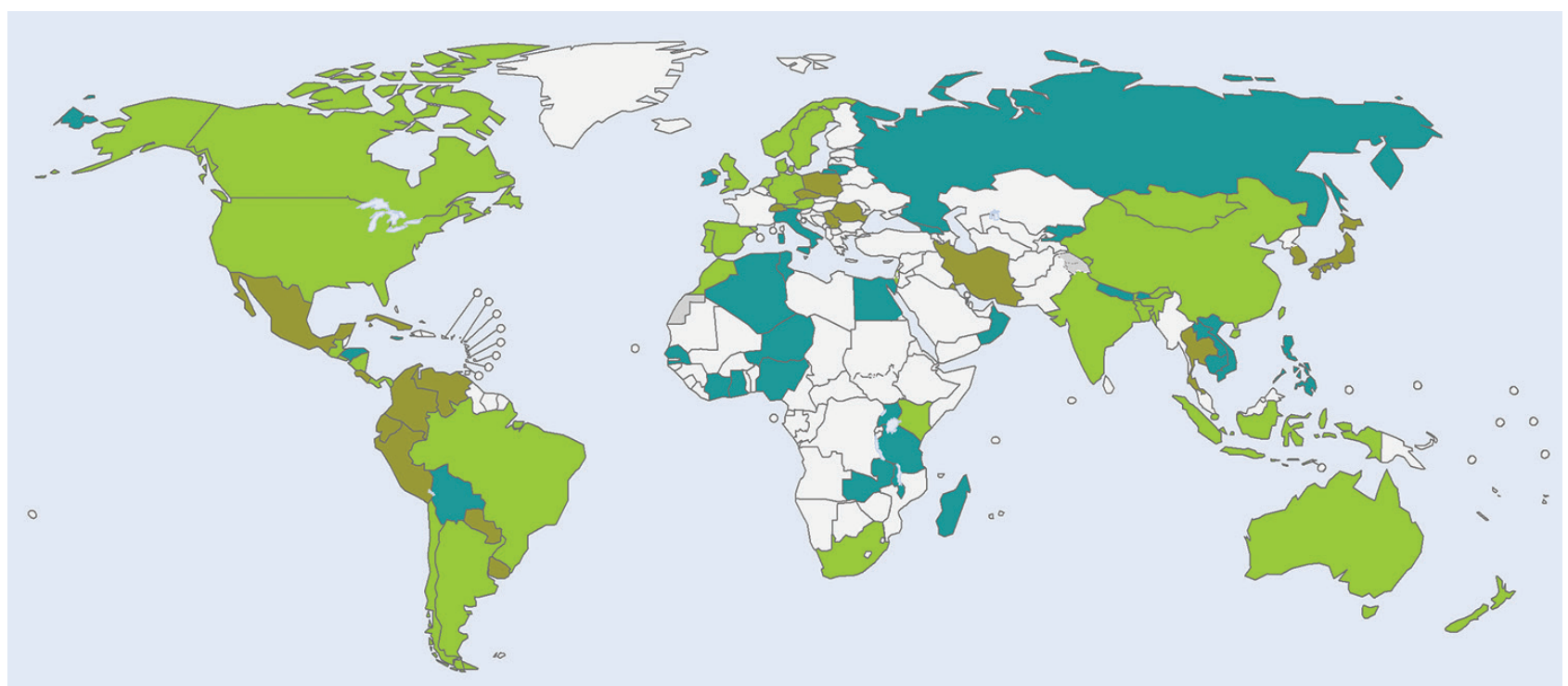

Figure. Countries with burden of disease estimates that have agreed to share data for the global estimate of influenza mortality and influenza-associated hospitalizations, as of April 2017: blue, morbidity estimates; brown, mortality estimates; green, morbidity and mortality estimates; white, data not available.

mapping existing knowledge from published literature to enable easier access to available data and identify key remaining gaps. Finally, WHO is developing a collection of economic tools to support the use of disease burden data to estimate the overall costs, the cost of vaccination programs, and the cost-effectiveness of vaccination.

In addition, other global partners are working in this area. The US Centers for Disease Control and Prevention has established collaborations with $>50$ countries around the world to strengthen surveillance and laboratory testing capacities, including expanding global capacity for genetic sequencing, that have produced data on influenza epidemiology and disease burden. The Multinational Influenza Seasonal Mortality Study (37), coordinated by the Fogarty Center at the US National Institutes of Health, has been working with countries to estimate influenza mortality from diverse settings since 2001. Institute Pasteur and Agence de Médecine Préventive have worked in low-income countries in Africa to build surveillance capacity. More recently, the Global Health Security Agenda has increased resources to many developing countries to strengthen surveillance and response capabilities that will also lead to new data on the relative burden of influenza compared with other infectious diseases. The European Center for Disease Control has developed free software that supports countries in the region to estimate the burden of influenza and other infectious diseases (38). These efforts have led to a substantial increase in country-specific estimates of burden in the past 5 years and promise to lead to many more in the next 1-2 years.

Much has been accomplished, and in the next few years a more complete picture of the burden of influenza will be available. However, more work will still be needed if we are to measure the full burden of influenza and, more important, the preventable burden. This knowledge will enable decision-makers to weigh the value of vaccination and encourage the use of antiviral drugs against myriad other health needs in their countries, as well as providing additional impetus for the development of newer, more effective treatments and vaccines. Vaccine probe studies have been proposed as a method to measure the preventable fraction of disease burden, focusing the studies on outcomes of greatest public health interest (e.g., pneumonia and death rates). Whether vaccine probe studies could be designed sufficiently to account for the variable and relatively modest vaccine efficacy and variability in annual disease burden that is characteristic of influenza is uncertain but should be further discussed (39). Finally, the year-to-year variability in disease burden requires that data be collected over multiple years and that new methodologic approaches be developed and validated to measure burden in settings with year-round circulation of influenza (40)

\section{Conclusions}

Influenza has long been a compelling example of a global pandemic threat, but the annual disease burden has been relatively underappreciated, leading to missed opportunities for disease reduction and prevention. Convincing evidence of seasonal burden of disease in more settings and for a wider array of influenza outcomes will be the foundation of arguments for strengthening programs to control annual influenza and to reduce the threat of future pandemics $(41,42)$. 


\section{About the Author}

Dr. Bresee is at the Office of the Associate Director for Global Health Affairs in the Influenza Division, National Center for Immunization and Respiratory Diseases, Centers for Disease Control and Prevention, and leads the Partnership for Influenza Vaccine Introduction at the Task Force for Global Health in Atlanta, Georgia. He is an epidemiologist and pediatrician whose current work focuses on influenza, influenza vaccine issues throughout the world, and US influenza vaccine policy.

\section{References}

1. Monto A, Sellwood C. History and epidemiologic features of pandemic influenza. In: Van-Tam J, Sellwood C, editors. Pandemic influenza. Boston: CABI; 2013. p. 40-9.

2. Dowdle WR. Influenza immunoprophylaxis after 30 years' experience In: Nayak DP, editor. Genetic variation among influenza viruses. New York: Academic Press, Inc.; 1981. p. 525-34.

3. Commission on Influenza. A clinical evaluation of vaccination against influenza. JAMA. 1944;124:982-5. http://dx.doi.org/ 10.1001/jama.1944.62850140004008

4. Nguyen-Van-Tam JS, Bresee JS. Pandemic preparedness and response. In: Webster RG, Monto AS, Braciale TJ, Lamb RA, editors. Textbook of influenza. Sussex (UK): John Wiley and Sons; 2013. p. 453-69.

5. Viboud C, Miller M, Olson D, Osterholm M, Simonsen L. Preliminary estimates of mortality and years of life lost associated with the $2009 \mathrm{~A} / \mathrm{H} 1 \mathrm{~N} 1$ pandemic in the US and comparison with past influenza seasons. PLoS Curr. 2010;2:RRN1153. http://dx.doi.org/10.1371/currents.RRN1153

6. Iuliano AD, Roguski KM, Chang HH, Muscatello DJ, Palekar R, Tempia S, et al.; Global Seasonal Influenza-associated Mortality Collaborator Network. Estimates of global seasonal influenza-associated respiratory mortality: a modelling study. Lancet. 2018;391:1285-300. http://dx.doi.org/10.1016/ S0140-6736(17)33293-2

7. World Health Organization. Up to 650000 people die of respiratory diseases linked to seasonal flu each year [cited 2017 Dec 19]. http://www.who.int/mediacentre/news/releases/2017/seasonal-flu

8. Kostova D, Reed C, Finelli L, Cheng PY, Gargiullo PM, Shay DK, et al. Influenza illness and hospitalizations averted by influenza vaccination in the United States, 2005-2011. PLoS One. 2013;8:e66312. http://dx.doi.org/10.1371/journal.pone.0066312

9. Osterholm MT, Kelley NS, Sommer A, Belongia EA. Efficacy and effectiveness of influenza vaccines: a systematic review and meta-analysis. Lancet Infect Dis. 2012;12:36-44. http://dx.doi.org/10.1016/S1473-3099(11)70295-X

10. Palache A, Oriol-Mathieu V, Fino M, Xydia-Charmanta M; Influenza Vaccine Supply task force (IFPMA IVS). Seasonal influenza vaccine dose distribution in 195 countries (2004-2013): little progress in estimated global vaccination coverage. Vaccine. 2015;33:5598-605. http://dx.doi.org/10.1016/ j.vaccine.2015.08.082

11. Kieny MP, Costa A, Hombach J, Carrasco P, Pervikov Y, Salisbury D, et al. A global pandemic influenza vaccine action plan. Vaccine. 2006;24:6367-70. http://dx.doi.org/10.1016/ j.vaccine.2006.07.021

12. World Health Organization. A checklist for pandemic influenza risk and impact management: building capacity for pandemic response: 2018 update. Geneva: The Organization; 2018. p. 1-59 [cited 2018 Mar 3]. http://www.who.int/influenza/preparedness/ pandemic/influenza risk management checklist 2018

13. Katz MA, Schoub BD, Heraud JM, Breiman RF, Njenga MK, Widdowson MA. Influenza in Africa: uncovering the epidemiology of a long-overlooked disease. J Infect Dis. 2012;206(Suppl 1):S1-4. http://dx.doi.org/10.1093/infdis/jis548

14. Chadha MS, Potdar VA, Saha S, Koul PA, Broor S, Dar L, et al. Dynamics of influenza seasonality at sub-regional levels in India and implications for vaccination timing. PLoS One. 2015;10:e0124122. http://dx.doi.org/10.1371/journal.pone.0124122

15. Saha S, Chadha M, Al Mamun A, Rahman M, Sturm-Ramirez K, Chittaganpitch $\mathrm{M}$, et al. Influenza seasonality and vaccination timing in tropical and subtropical areas of southern and southeastern Asia. Bull World Health Organ. 2014;92:318-30. http://dx.doi.org/10.2471/BLT.13.124412

16. Hirve S, Newman LP, Paget J, Azziz-Baumgartner E, Fitzner J, Bhat N, et al. Influenza seasonality in the tropics and subtropicswhen to vaccinate? PLoS One. 2016;11:e0153003. http://dx.doi.org/10.1371/journal.pone.0153003

17. Hirve S, Krishnan A, Dawood FS, Lele P, Saha S, Rai S, et al. Incidence of influenza-associated hospitalization in rural communities in western and northern India, 2010-2012: a multi-site population-based study. J Infect. 2015;70:160-70. http://dx.doi.org/ 10.1016/j.jinf.2014.08.015

18. Nair H, Brooks WA, Katz M, Roca A, Berkley JA, Madhi SA, et al. Global burden of respiratory infections due to seasonal influenza in young children: a systematic review and meta-analysis. Lancet. 2011;378:1917-30. http://dx.doi.org/10.1016/ S0140-6736(11)61051-9

19. McMorrow ML, Emukule GO, Njuguna HN, Bigogo G, Montgomery JM, Nyawanda B, et al. The unrecognized burden of influenza in young Kenyan children, 2008-2012. PLoS One. 2015;10:e0138272. http://dx.doi.org/10.1371/journal.pone.0138272

20. Lafond KE, Nair H, Rasooly MH, Valente F, Booy R, Rahman M, et al.; Global Respiratory Hospitalizations-Influenza Proportion Positive (GRIPP) Working Group. Global role and burden of influenza in pediatric respiratory hospitalizations, 1982-2012: a systematic analysis. PLoS Med. 2016;13:e1001977. http://dx.doi.org/10.1371/journal.pmed.1001977

21. Cohen C, Simonsen L, Kang JW, Miller M, McAnerney J, Blumberg L, et al. Elevated influenza-related excess mortality in South African elderly individuals, 1998-2005. Clin Infect Dis. 2010;51:1362-9. http://dx.doi.org/10.1086/657314

22. Xeuatvongsa A, Mirza S, Winter C, Feldon K, Vongphrachanh P, Phonekeo D, et al. The Lao experience in deploying influenza $\mathrm{A}(\mathrm{H} 1 \mathrm{~N} 1) \mathrm{pdm} 09$ vaccine: lessons made relevant in preparing for present day pandemic threats. PLoS One. 2015;10:e0121717. http://dx.doi.org/10.1371/journal.pone.0121717

23. Ropero-Alvarez AM, Kurtis HJ, Danovaro-Holliday MC, Ruiz-Matus C, Andrus JK. Expansion of seasonal influenza vaccination in the Americas. BMC Public Health. 2009;9:361-6. http://dx.doi.org/10.1186/1471-2458-9-361

24. Owusu JT, Prapasiri P, Ditsungnoen D, Leetongin G, Yoocharoen P, Rattanayot J, et al. Seasonal influenza vaccine coverage among high-risk populations in Thailand, 2010-2012. Vaccine. 2015;33:742-7. http://dx.doi.org/10.1016/j.vaccine.2014.10.029

25. World Health Organization. Vaccines against influenza WHO position paper-November 2012. Wkly Epidemiol Rec. 2012;87:461-76.

26. Jamieson DJ, Honein MA, Rasmussen SA, Williams JL, Swerdlow DL, Biggerstaff MS, et al.; Novel Influenza A (H1N1) Pregnancy Working Group. H1N1 2009 influenza virus infection during pregnancy in the USA. Lancet. 2009;374:451-8. http://dx.doi.org/10.1016/S0140-6736(09)61304-0

27. Mosby LG, Rasmussen SA, Jamieson DJ. 2009 pandemic influenza A (H1N1) in pregnancy: a systematic review of the literature. Am J Obstet Gynecol. 2011;205:10-8. http://dx.doi.org/10.1016/ j.ajog.2010.12.033

28. Kallenburg J, Nguyen A. Vaccine investment strategy: report to the GAVI Alliance Board, 11-12, 2013 [cited 2017 Dec 19]. 
https://www.gavi.org/about/governance/gavi-board/ minutes/2013/11-jun/presentations/06---vaccineinvestment-strategy

29. Cohen AL, McMorrow M, Walaza S, Cohen C, Tempia S, Alexander-Scott M, et al. Potential impact of co-infections and co-morbidities prevalent in Africa on influenza severity and frequency: a systematic review. PLoS One. 2015;10:e0128580. http://dx.doi.org/10.1371/journal.pone.0128580

30. Peasah SK, Azziz-Baumgartner E, Breese J, Meltzer MI, Widdowson MA. Influenza cost and cost-effectiveness studies globally—a review. Vaccine. 2013;31:5339-48. http://dx.doi.org/ 10.1016/j.vaccine.2013.09.013

31. World Health Ornaization. WHO Public Health Research Agenda for Influenza: 2017 update [cited 2018 May 8]. http://www.who.int/influenza/resources/research/ publication_research_agenda_2017

32. World Health Organization. A manual for estimating disease burden associated with seasonal influenza [cited 2017 Dec 19]. http://www.who.int/influenza/resources/publications/ manual burden of disease

33. World Health Organization. WHO manual for estimating the economic burden of seasonal influenza. 2016 [cited 2017 Dec 19] http://www.who.int/immunization/documents/financing/ who_ivb_16.04

34. Lee VJ, Ho ZJM, Goh EH, Campbell H, Cohen C, Cozza V, et al.; WHO Working Group on Influenza Burden of Disease. Advances in measuring influenza burden of disease. Influenza Other Respi Viruses. 2018;12:3-9. http://dx.doi.org/10.1111/irv.12533

35. Fell DB, Savitz DA, Kramer MS, Gessner BD, Katz MA, Knight M, et al. Maternal influenza and birth outcomes: systematic review of comparative studies. BJOG. 2017;124:48-59. http://dx.doi.org/10.1111/1471-0528.14143

36. Mertz D, Geraci J, Winkup J, Gessner BD, Ortiz JR, Loeb M. Pregnancy as a risk factor for severe outcomes from influenza virus infection: A systematic review and meta-analysis of observational studies. Vaccine. 2017;35:521-8. http://dx.doi.org/ 10.1016/j.vaccine.2016.12.012

37. National Institutes of Health. Multinational Influenza Seasonal Mortality Study [cited 2018 May 8]. http://misms.net

38. Colzani E, Cassini A, Lewandowski D, Mangen MJ, Plass D, McDonald SA, et al. A software tool for estimation of burden of infectious diseases in Europe using incidence-based disability adjusted life years. PLoS One. 2017;12:e0170662. http://dx.doi.org/10.1371/journal.pone.0170662

39. Gessner BD, Brooks WA, Neuzil KM, Vernet G, Bright RA, Tam JS, et al. Vaccines as a tool to estimate the burden of severe influenza in children of low-resourced areas (November 30December 1, 2012, Les Pensieres, Veyrier-du-Lac, France). Vaccine. 2013;31:3222-8. http://dx.doi.org/10.1016/ j.vaccine.2013.05.017

40. Lambach P, Alvarez AM, Hirve S, Ortiz JR, Hombach J, Verweij M, et al. Considerations of strategies to provide influenza vaccine year round. Vaccine. 2015;33:6493-8. http://dx.doi.org/10.1016/j.vaccine.2015.08.037

41. Zhang W, Hirve S, Kieny MP. Seasonal vaccines - Critical path to pandemic influenza response. Vaccine. 2017;35:851-2. http://dx.doi.org/10.1016/j.vaccine.2016.12.056

42 Gellin BG, Ampofo WK. Seasonal and pandemic influenza vaccine: demand, supply and vaccine availability. Vaccine. 2014;32:7037-9. http://dx.doi.org/10.1016/ j.vaccine.2014.10.062

Address for correspondence: Joseph Bresee, Centers for Disease Control and Prevention, 1600 Clifton Rd NE, Mailstop A20, Atlanta, GA 30329-4027, USA; email: jbresee@cdc.gov
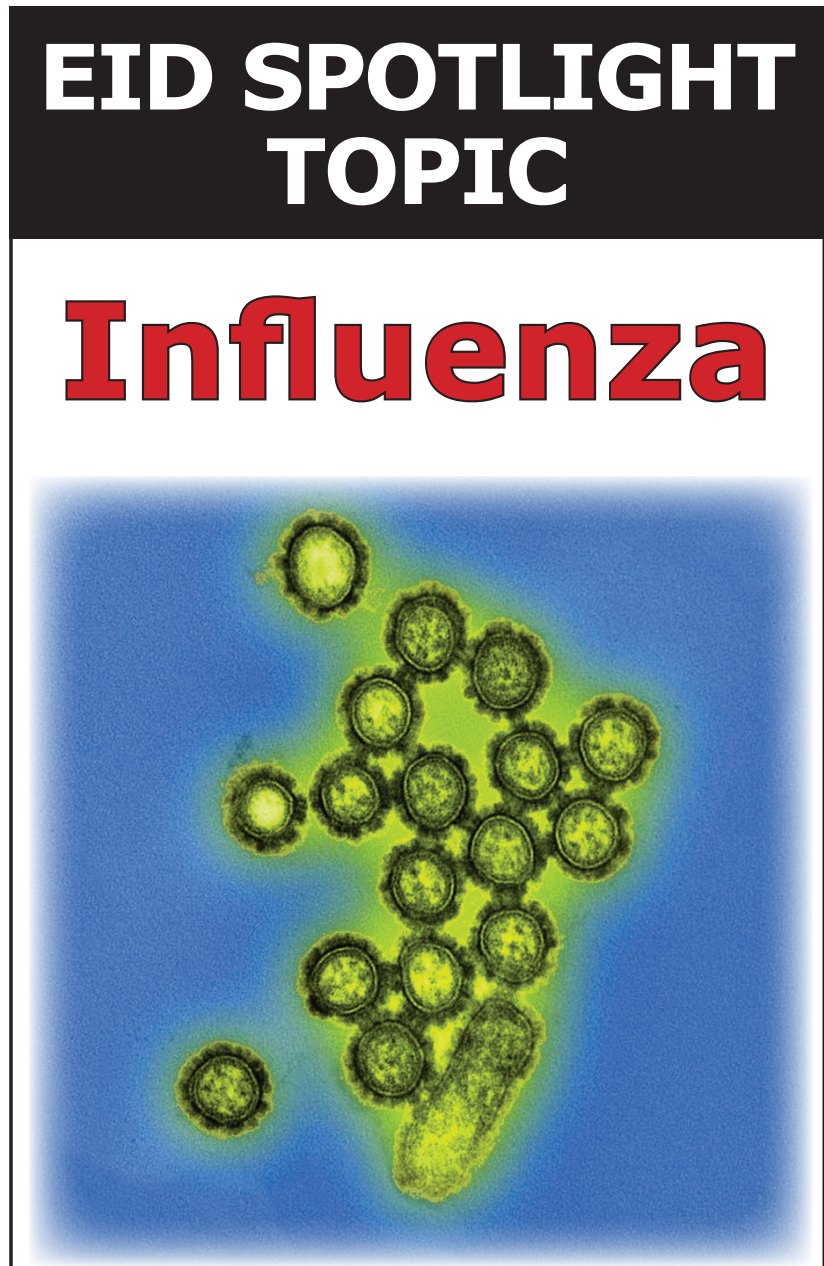

Influenza (flu) is a contagious respiratory illness caused by influenza viruses. It can cause mild to severe illness. Serious outcomes of flu infection can result in hospitalization or death. Some people, such as older people, young children, and people with certain health conditions, are at high risk for serious flu complications. The best way to prevent the flu is by getting vaccinated each year.

\section{http://wwwnc.cdc.gov/eid/ page/influenza-spotlight}

